\title{
Nephrotic Syndrome in Tuberous Sclerosis - A Rare Presentation
}

\author{
Vijay Kumar' ${ }^{1}$, Sanjay Kumar², Devdarshan Nitin Gandhi³ , Mani Kant Kumar ${ }^{4}$
}

1, 2, 3, 4 Department of Paediatrics, Narayan Medical College and Hospital, Jamuhar, Sasaram, Rohtas, Bihar, India.

\section{INTRODUCTION}

Tuberous Sclerosis Complex (TSC) is a dominant multisystem genetic disorder, which is also known as Bourneville's disease. Prevalence of tuberous sclerosis is approximately 1 in 6000 births affecting both sexes and all ethnic groups.1,2 Tuberous sclerosis complex caused by an inactivation mutation of either $T_{S C} C_{1}$ gene located on chromosomal locus 9q34.3 or $T_{S C}$ gene located on chromosome 16 (chromosomal locus 16p 13.3) which encode protein hamartin and tuber in respectively. 1,3 Tuberous sclerosis complex characterized by the triad of facial angiofibroma, intellectual disabilities. It is a multi-system disorder affecting the brain, skin, kidneys, heart, eyes, and lungs. In various case series renal involvement were observed in 48 to $80 \%$ of TSC patients and may be in the form of Angio-Myo-Lipomas (AML), polycystic kidney disease, and renal cell carcinoma ${ }^{1,3}$ but the nephrotic syndrome is a very rare presentation. ${ }^{4}$ Here we report a case of a 5 -year male child brought to our institute as a case of nephrotic syndrome, in which there were also features of tuberous sclerosis.

\section{PRESENTATION OF CASE}

A 5-year-old male child, a resident of Aurangabad, Bihar, a product of marriage with uneventful perinatal period brought to our paediatric OPD (Out Patient Department) with complaints of progressive generalized swelling which started from the face and progressed to the whole body in 4 days. There was also history of abdominal swelling and scrotal swelling. There is a family history suggestive of TSC in mother. There was no history of developmental delay. There was no history of seizure till admission in our institute.

On examination at admission he was conscious, active, alert, his vitals were stable, and blood pressure was within normal limit for age. He had mild pallor, generalized pitting oedema and massive scrotal swelling. There were papules on the region (Adenoma sebaceum) as shown in Figure 1, ash leaf macules in Figure 2 and shagreen patch over the lumbosacral region as shown in Figure 2 and a large angiofibromatous lesion over left forehead.

On abdomen examination: abdomen mildly distended, non-tender, shifting dullness present without any organomegaly, rest of the systemic examination were unremarkable. Ophthalmological evaluation by ophthalmologist was normal.

\author{
Corresponding Author: \\ Dr. Mani Kant Kumar, \\ Department of Pediatrics, \\ Narayan Medical College \\ and Hospital, Jamuhar, \\ Sasaram, Rohtas, Bihar, \\ India. \\ E-mail: manikant7@yahoo.com
}

DOI: $10.14260 / j e m d s / 2020 / 827$

How to Cite This Article:

Kumar V, Kumar S, Gandhi DN, et al. Nephrotic syndrome in tuberous sclerosisa rare presentation. J Evolution Med Dent Sci 2020;9(49):3770-3772, DOI: $10.14260 /$ jemds/2020/827

Submission 19-06-2020,

Peer Review 19-10-2020

Acceptance 26-10-2020,

Published 07-12-2020.

Copyright (c) 2020 JEMDS. This is an open access article distributed under Creative Commons Attribution License [Attribution 4.0 International (CC BY 4.0)] 

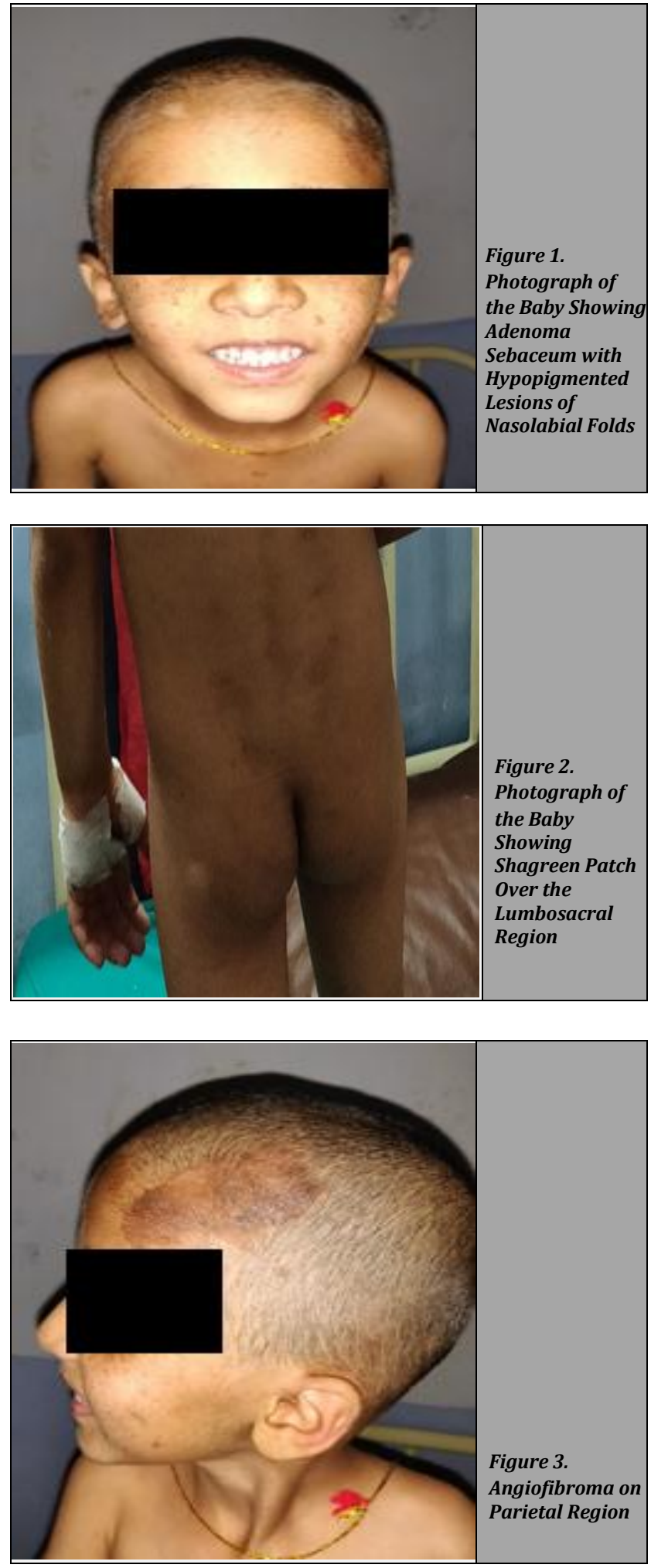

On investigation mild microcytic hypochromic anaemia (Hb: 9.8 gm \%), with normal total leukocytes, differential count and platelets count was revealed. His serum sodium, potassium, calcium, SGPT (Serum glutamic pyruvic transaminase), serum albumin, blood urea and serum creatinine were normal. On urine routine and microscopic examination urine protein $4+$, no RBC, no RBC cast and no pus cells, urine culture and sensitivity was sterile. His total serum protein $5 \mathrm{gm} \mathrm{/} \mathrm{dL,} \mathrm{while} \mathrm{serum} \mathrm{albumin:} 1.2 \mathrm{gm} \mathrm{/} \mathrm{dL}$ (Hypoalbuminemia), total cholesterol levels: $605.7 \mathrm{mg} / \mathrm{dL}$. Quantitative urine protein analysis revealed 24-hour urinary protein: $2196 \mathrm{mg} / 24$ hours (> $40 \mathrm{mg} / \mathrm{m} 2$ / hour), USG
(Ultra-Sono-Graphy) whole abdomen: normal, Doppler study of renal vessels: normal, on neuroimaging MRI (Magnetic Resonance Imaging) brain showed increased signal intensities in subcortical area (subcortical tubers). In T2 weighted image in Figure 4, and in T1 weighted axial images showed hyperintense lesion in subependymal region consisted of subependymal nodules-suggestive of tuberous sclerosis.
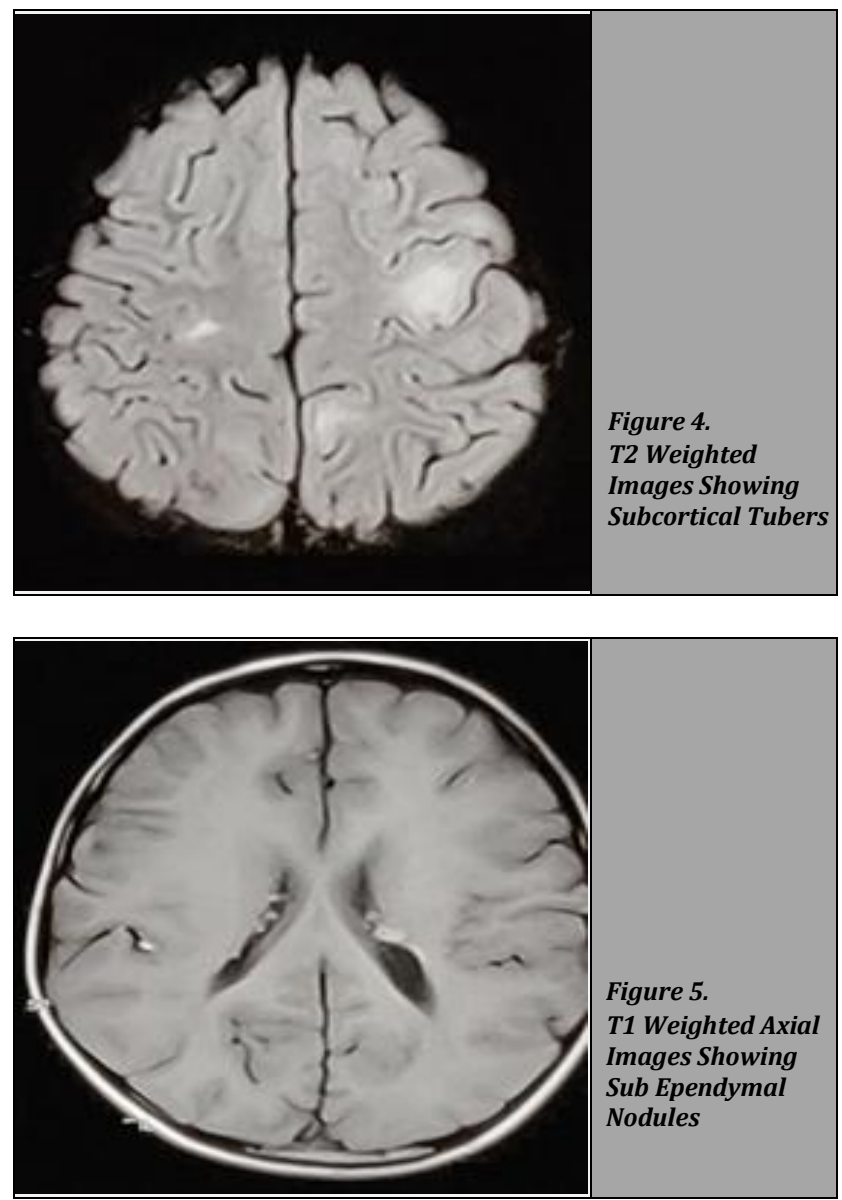

\section{DISCUSSION}

Although tuberous sclerosis is not a very uncommon genetic disorder, but association of nephrotic syndrome in a case of tuberous sclerosis is very rare especially in children. In world literature only few cases of nephrotic syndrome along with tuberous sclerosis was reported, majority in adults' ${ }^{4}$ Our case was also among such rare presentation of tuberous sclerosis with nephrotic syndrome.

\begin{tabular}{|cc|}
\hline Major Criteria & Minor Criteria \\
1. Cortical tuber & $\begin{array}{c}\text { 1. Cerebral white matter } \\
\text { migration lines }\end{array}$ \\
2. Sub-ependymal nodule & 2. Multiple dental pits \\
3. Facial angiofibroma or forehead plaque & 3. Gingival fibromas \\
4. Ungual or Periungual fibroma (non-traumatic) & 4. Bone cysts \\
5. Hypomelanotic macules (>3) & 5. Retinal achromatic patch \\
6. Shagreen patch & 6. Confetti skin lesions \\
7. Multiple retinal hamartomas & 7. Non-renal hamartomas \\
8. Cardiac rhabdomyoma & 8. Multiple renal cysts \\
9. Renal angiomyolipoma & 9. Hamartomatous rectal polyps \\
10. Pulmonary lymphangioleiomyomatosis & \\
\hline 11. Sub-ependymal giant cell astrocytoma \\
\hline Table 1 Diagnostic Criteria for Tuberous Sclerosis \\
\hline
\end{tabular}


Tuberous sclerosis complex is a rare hereditary disorder with a varied phenotypic manifestation. The diagnostic criteria for TSC consists of a set of major and minor diagnostic features in Table 1. In any suspected patient, definitive tuberous sclerosis complex is diagnosed when a suspected patient has at least two major or one major plus two minor features. ${ }^{1,5}$

Our case fulfilled above criteria to be diagnosed as tuberous sclerosis as having 5 major criteria subcortical tubers, subependymal nodules, facial angiofibroma or forehead plaque, shagreen patch and ash leaf macules. In various studies the prevalence of dermatological manifestations in TSC were facial angiofibroma.

The majority of patients with tuberous sclerosis presented first time with generalized seizure, however, our case did not have history of seizure till date, so parents were explained regarding risk to develop seizure in future.

In patients with these criteria and fulfilled clinical diagnosis of definitive TSC, may be also asked for genetic study to detect the mutation. In our case we counseled the parents of the patient regarding the need of genetic analysis for mutation detection in the gene but due to resource limitation, parents were not willing for genetic analysis.

Patient with tuberous sclerosis complex had frequent renal manifestation ranging from $34 \%$ to upto $80 \%$ in different studies. The two most common renal pathologies seen in TSC are Angio-Myo-Lipomas (AMLs) - 34 to $80 \%$ and renal cysts $14-32 \%$. Although uncommon but when TSC co-exists with polycystic kidney disease, carries a poor outcome for renal survival.1,3

Although patients with TSC had frequent renal manifestation, but manifestation as nephrotic syndrome is a very rare association ${ }^{2}$ especially in paediatric age group patient, and our case was as such a rare manifestation of tuberous sclerosis in children. Our patient had progressive generalized oedema, nephrotic range proteinuria ( $>40 \mathrm{mg} /$ $\mathrm{m}^{2}$ / hour), hypercholesterolaemia, and hypo-albuminaemia fulfilling the diagnosis of nephrotic syndrome. Hence, the patient was diagnosed as a case of tuberous sclerosis with nephrotic syndrome. So while treating a patient with tuberous sclerosis, parents also should be counseled regarding the risk of nephrotic syndrome and treating paediatrician should keep monitoring for nephrotic syndrome in follow up of the patient.

\section{CONCLUSIONS}

Although renal involvement is very common in tuberous sclerosis, nephrotic syndrome is a rare presentation. So, while treating a patient with tuberous sclerosis, parents also should be counseled regarding the risk of nephrotic syndrome and treating paediatrician should keep monitoring for nephrotic syndrome in follow up of the patient.

Financial or other competing interests: None.

Disclosure forms provided by the authors are available with the full text of this article at jemds.com.

\section{REFERENCES}

[1] Korula S, Ekbote A, Kumar N, et al. Renal manifestations of tuberous sclerosis among children: an Indian experience and review of the literature. Clin Kidney J 2014;7(2):134-7.

[2] Shrestha S, Shrestha S, Ojha AR. Case report on tuberous sclerosis. Journal of Kathmandu Medical College 2013;2(4):208-10.

[3] Rakowski SK, Winterkorn EB, Paul E, et al. Renal manifestations of tuberous sclerosis complex: incidence, prognosis and predictive factors. Kidney Int 2006;70(10):1777-82.

[4] Sauter M, Berger F, Fischereder M. Nephrotic syndrome in a woman with tuberous sclerosis. Dtsch Med Wochenschr 2014;139(20):1046-50.

[5] Crino PB, Nathanson KL, Henske EP. The Tuberous sclerosis complex. N Engl J Med 2006;355(15):1345-56. 